\title{
O DEREITO A UNHA VIVENDA ASEQUIBLE, ACCESIBLE E DIGNA NA CIDADE SUSTENTABLE ${ }^{1}$
}

The right to affordable, accessible and decent housing in the sustainable city

\section{DOI: http://dx.doi.org/10.15304/dereito.29.Ext.6672}

AndREi Quintiá PASTRANA

Investigador Predoutoral

Universidade de Santiago de Compostela

ORCID ID: https://orcid.org/0000-0003-3005-7318

a.quintia@usc.gal

\section{CRISE FINANCEIRA E EMERXENCIA HABITACIONAL}

A crise financeira do 2007 axitou os mercados globais da hipoteca. O impacto foi devastador nos países cuxo sistema de acceso á vivenda dependía do mercado do crédito. Neses Estados, como foi o caso de España, a crise financeira manifestouse, ademais, coma unha crise habitacional.

Nos últimos anos, a investigación xurídica estalle a prestar unha atención especial ao estudo desta cuestión. Cada vez é maior a densidade de publicacións e de foros especializados na materia. Unha tendencia que probablemente garde relación coa virulencia coa que a crise impactou sobre a oferta habitacional en España.

A privación total da vivenda habitual é unha das consecuencias máis visibles deste contexto de emerxencia. As cifras son reveladoras. Segundo o Consello Xeral do Poder Xudicial, entre 2007 e 2016 iniciáronse 720.000 procedementos de execución hipotecaria, que rematarían co efectivo desaloxo de 327.000 fogares no mesmo período.

Os efectos da crise poden apreciarse, tamén, no acusado incremento do senfogarismo. O último informe do INE sinala que entre 2014 e 2016 o número de ingresos nos centros de atención a persoas sen fogar aumentou un $20,5 \%$. Mais o fenómeno non sempre se manifesta como a desposesión total do fogar. Existen moitos exemplos de "senfogarismo oculto" que tamén é preciso considerar.

É o caso, por exemplo, das familias que se ven obrigadas a compartir un inmoble para facer fronte aos gastos de maneira conxunta. Segundo o INE, no ano 2018 había 1.121.900 fogares compostos por máis dun núcleo familiar. Outro exemplo é a tardía emancipación das persoas mozas. Pois segundo o informe Esenciales da Fundación BBVA de 2019, o 65\% das mozas e mozos de entre 16 e 34 anos viven cos seus pais. Un aumento de dez puntos desde o ano 2009.

A Constitución española garante o dereito a unha vivenda digna e adecuada no seu art. 47. Así mesmo, varias Comunidades Autónomas incorporaron este título no seu articulado entre os anos 2006-2007. Non obstante, o dereito a unha vivenda digna non é un título directamente

\footnotetext{
${ }^{1}$ Este traballo encádrase no Proxecto «Vulnerabilidad social, crisis económica y derecho a la vivienda. Las políticas públicas de garantía social» (DER2016-79913-R).
} 
opoñible, senón un dereito de "configuración legal"2. É dicir, que a súa aplicación efectiva depende dun desenvolvemento posterior que defina o seu alcance e efectos.

En vista do contexto de crise, once Comunidades Autónomas despregaron, a partir de 2013, un proceso de reformas dirixidas a efectivizar o dereito á vivenda. Estas marcaron un xiro na política habitacional do Estado e, tamén, na actitude que as Autonomías mantiñan con respecto á súa propia competencia exclusiva en materia de vivenda (art. 148.1.3 $\mathrm{CE}$ ). Pois, até o momento o desenvolvemento deste dereito fora escaso en España.

A Comunidade Autónoma de Andalucía inaugurou o proceso de cambio coa aprobación do Decreto-lei 6/2013, de 9 de abril, posteriormente validado na Lei 4/2013 de 1 de outubro. Cómpre advertir que esta reforma foi impugnada polo Goberno central ante o Tribunal Constitucional, alegando a invasión das competencias estatais en materia económica e sobre a regulación bancaria e do crédito. Do mesmo xeito serían posteriormente recorridas, tamén, as restantes normas.

Non nos ocupa aquí analizar a liña xurisprudencial que se desenvolveu a partir destes recursos, pois xa foi comentada en detalle noutros traballos ${ }^{3}$. Porén, si cabe sinalar que esta acabaría por consolidarse co cambio de Goberno de 2016 e as sentenzas do Tribunal Constitucional 16/2018, de 22 de febreiro e 80/2018, de 5 de xullo.

Tras estes pronunciamentos asentouse un entendemento do reparto competencial en materia de vivenda que abriu unha nova época de políticas autonómicas de vivenda. En síntese, as Autonomías dispoñen de plena competencia para articular calquera tipo de medida, sexa de fomento ou de intervención. Iso si, sempre que non interfira directamente na política crediticia e económica fixada polo Estado.

As reformas son bastante semellantes entre si xa que en grande medida as comunidades autónomas seguiron un patrón de emulación das reformas precedentes e as consecuencias da súa eventual inconstitucionalidade. Porén, entre elas distínguense dúas aproximacións claramente diferenciadas. Sucintamente podemos afirmar que unha delas se caracteriza por unha aproximación máis asistencialista, orientada especialmente a atender as situacións de emerxencia que provocou a crise financeira (p.ex medidas antidesafiuzamentos, asistencia especial a persoas con forte carga da débeda, etc.) e, polo xeral, menos intervencionista. Neste primeiro grupo encadraríanse, por exemplo, Andalucía ou as Illas Canarias. A outra, cun alcance máis estrutural destinada a asentar unha nova política de vivenda pública cunha intervención máis intensa na oferta habitacional, encabezada por Valencia e Cataluña ${ }^{4}$.

Correspóndelle á investigación xurídica explorar este novo campo. É necesario estudar o abanico de posibilidades que se abre para o desenvolve-

\footnotetext{
2 M. VAQUER CABALLERÍA, La eficacia y la efectividad del derecho a la vivienda en España, Iustel, Madrid, 2011

${ }^{3}$ A. NOGUEIRA LÓPEZ \& A. QUINTIÁ PASTRANA, "The Spanish housing crisis: between autonomic social action and neoliberal recentralization" en VV.AA (Vols, M. y Schmid, C., Eds.) Houses, Homes and the Law, La Haya, Eleven, 2019

${ }^{4}$ N. PALEO MOSQUERA \& A. QUINTIÁ PASTRANA, "Las políticas de vivienda desde una perspectiva multinivel: un análisis comparado de la legislación autonómica" en VV.AA (N.Paleo Mosquera, Ed.), Gente sin casa y casas sin gente. Políticas y derecho a la venda, Tirant lo Blanch, Valencia, 2020
} 
mento da competencia autonómica en materia de vivenda. Neste sentido resulta de interese a análise das reformas habitacionais aprobadas nos últimos anos. Sen menosprezar, tampouco, as interesantes achegas da metodoloxía comparada do Dereito e o estudo de outras experiencias e do seu encaixe no noso ordenamento.

\section{Un contexto complexo}

É preciso sinalar neste punto que a crise actual singularízase, ademais, pola súa profunda complexidade. As vellas problemáticas (asequibilidade dos inmobles, construción e asignación de vivenda pública, planificación urbanística) mestúranse con novos desafíos (sustentabilidade urbana, medre exponencial do turismo, plataformas dixitais). Entre estes novos desafíos destaca a converxencia da chamada economía de plataformas e a explotación das vivendas para uso turístico.

A economía de plataformas é un novo sistema de mercado dirixido ao aproveitamento e á xestión dun "tipo particular de materia prima: os datos $^{\prime \prime}$. A cidade é unha fonte inmensa de información. Porén, até a chegada da revolución dixital, moitos destes datos estaban desaproveitados. Por exemplo: descoñecíase con precisión o número e o estado das vivendas baleiras; a demanda real de prazas residenciais e turísticas, etc. Esta falta de información obstaculizaba o aproveitamento dos recursos da cidade. Mais, coa economía de plataformas todo isto mudou.

Existe un sector de plataformas dixitais especializadas en conectar aos particulares que buscan "un rendemento económico temporal pola súa vivenda habitual ou pola súa segunda vivenda con aqueles que buscan alternativas aos hoteis tradicionais"

O interesante destas plataformas está en que que facilitan a explotación das vivendas infraocupadas. Pois o uso da tecnoloxía outorga "confianza e reciprocidade" ao intercambio deste tipo de recursos e reduce "de maneira significativa os custes de coordinación e transacción"7. Desde ese punto de vista, a chegada destas plataformas é interesante porque permiten mobilizar espazos habitacionais que antes estaban infrautilizados ${ }^{8,9}$. Non obstante, tamén produce certas externalidades negativas que condicionan o acceso á vivenda.

Diversos estudos confirman que hai unha certa correlación entre o nivel de implantación destas plataformas e o encarecemento dos alugueiros ${ }^{10,11}$, así coma a aceleración de procesos de expulsión e substitución poboacional212.

\footnotetext{
${ }^{5}$ N. SRNICEK, Capitalismo de plataformas, Caja Negra Editora, Buenos Aires, 2018

${ }^{6}$ A. MARÍA DE LA ENCARNACIÓN ,"El alojamiento colaborativo: Viviendas de uso turístico y plataformas virtuales", REALA, 5, 51,2016

7 A. CAÑIGUERAL BAGÓ, "Hacia una economía de plataformas responsable", Cuadernos Económicos de ICE, 97, 25, 2019

8 DOMÉNECH PASCUAL, G., "Economía colaborativa y Administración local", Anuario de Gobierno Local, 16, 35-66, 2015

9 DOMÉNECH PASCUAL, G. (2017) 'La regulación de las viviendas de uso turístico', Anuario de Derecho Municipal, 11, 43-73, 2017

${ }^{10}$ K. BARRON, E. KUNG, \& D. PROSERPIO, "The Effect of Home-Sharing on House Prices and Rents: Evidence from Airbnb", Working paper, 2020, <https://ssrn.com/abstract=3006832>

${ }_{11}$ M-A. Garcia-López, et al., "Do Short-Term Rental Platforms Affect Housing Markets? Evidence From Airbnb in Barcelona", Working paper, 2019 <doi: 10.2139/ssrn.3428237>

12 D. WACHSMUTH \& A. WEISLER, "Airbnb and the rent gap: Gentrification through the sharing economy", Environment and Planning A, 50(6), 1147-1170, 2018
} 
A aproximación a esta problemática é complexa. En primeiro lugar porque se trata dun fenómeno no que converxen múltiples dimensións. As plataformas de xestión de vivendas de uso turístico afectan á oferta habitacional, mais tamén á oferta turística e ao dereito da competencia. Calquera intervención sobre este ámbito producirá efectos imprevistos noutras esferas. É difícil delimitar o modo e o grao de intervención sen producir efectos non desexados ou lesionar intereses constitucionalmente protexidos (p. ex 33, 38, 47 CE).

Habitamos o momento histórico das "sociedades complexas". Un mundo constituído por conxuntos de subsistemas sociais interdependentes e de intelixencia colectiva. Un contexto no que as responsabilidades individuais e as lóxicas causa-efecto teñen menos importancia ca antes. Por exemplo, como sinala Innerarity ${ }^{13}$, a burbulla inmobiliaria é un fenómeno complexo con "moitas remisións causais e diversas dimensións de responsabilidade", no que as "culpas propias" non se distinguen das "fatalidades sistémicas".

A investigación xurídica ten que adaptarse a esta complexidade se quere alcanzar o ritmo de evolución das problemáticas sociais. Cómpren reflexións poliédricas e transversais que recoñezan a pluralidade de polos e actores que actualmente operan nos tecidos sociais. De igual modo, é necesario derribar vellos muros e abrir canles entre disciplinas, materias e áreas de coñecemento. Pois as vellas categorías ríxidas e estancas flúen, hoxe, nun contexto de aceleración e interdependencia extrema.

\section{Que ofrece este monográfico?}

Este monográfico xurde do Congreso internacional sobre vivenda e vulnerabilidade que organizou a Rede Armela (http://redearmela.org), dirixida pola Dra. Alba Nogueira López, en Santiago de Compostela en outubro de 2019. Os traballos que se reúnen aquí son o resultado das aportacións que os autores expuxeron naquel encontro, enriquecidos co debate que se abriu no mesmo foro e a posterior reelaboración para a súa publicación despois dun proceso de avaliación anónima.

O obxectivo daquel Congreso era reflexionar sobre as diversas problemáticas que a cuestión habitacional enfronta nos últimos anos. Presentáronse múltiples traballos de disciplinas variadas (dereito, ciencias políticas, socioloxía) e perspectivas igualmente diversas. As publicacións que compoñen este monográfico recollen a complexidade daquel debate e das conclusións que se foron extraendo das distintas presentacións.

As persoas lectoras poden atopar aquí unha aproximación rica e heteroxénea á cuestión da vivenda na sociedade contemporánea. A utilidade desta aproximación radica na necesidade de articular respostas complexas ás problemáticas complexas que se nos presentan na actualidade. Este monográfico reúne un total de seis traballos que exploran diferentes dimensións do problema e están enfocados desde diferentes perspectivas xurídicas.

Inclúe aproximacións conceptuais tanto a categorías xa máis consolidadas como a outras máis novidosas. As temáticas son, igualmente, variadas. Por exemplo, no presente número explórase a configuración xurídica do de-

\footnotetext{
${ }_{13}$ D. INNERARITY, Una teoría de la democracia compleja. Gobernar en el siglo XXI, Galaxia Gutemberg, Barcelona, 2020
} 
reito á cidade no noso ordenamento, o desenvolvemento administrativo do dereito á vivenda, o impacto ambiental no sector habitacional, a accesibilidade, os procesos de "xentrificación" ou o impacto do fenómeno das vivendas de uso turístico.

O primeiro dos artigos presentado por Alejandra Boto, profesora de Dereito Administrativo da Universidade de Oviedo, analiza o concepto de "vivenda evolutiva" que introduciu a última reforma francesa en materia de accesibilidade e vivenda. Trátase dun estudo comparado que identifica dito concepto coma un criterio a priori regresivo, pois reduce o número de esixencias técnicas en relación cos estándares mínimos de accesibilidade na edificación.

Porén, como sinala a propia autora, os estándares formais non están realmente a ser aplicados na práctica. Neste sentido, a reforma pode ser útil para superar o grave problema da accesibilidade á vivenda no territorio galo. $\mathrm{O}$ artigo de Boto pon o foco no debate sobre a imposición de estándares formais a particulares para alcanzar obxectivos de política social. En particular, sobre se é mellor rebaixar os estándares técnicos para facilitar a consecución de obxectivos ou establecer niveis máis altos.

Así mesmo, neste contexto de cambio, o traballo de Boto ten especial relevancia. Por unha parte, porque as dimensións global e local dos procesos confúndense e as regulacións domésticas teñen importantes ramificacións alén das fronteiras. Por outra parte, porque a converxencia entre os Estados permite que que hoxe as análises sexan máis facilmente extrapolables ca nunca.

No segundo traballo, Gabriele Vestri explora os efectos dos procesos de expulsión residencial (xentrificación e turistificación) sobre o dereito de acceso a unha vivenda. Faino mediante un estudo de caso, o do Casco antigo de Sevilla e mediante a análise pormenorizada da regulación urbanísitca e habitacional que se lle aplica a esa área. O autor chega á conclusión de que estes procesos si son un obstáculo para o pleno exercicio do dereito. Pois, as normas vixentes, malia ter algúns puntos interesantes, non ofrecen unha solución integral suficiente.

O traballo de Vestri é unha interesante ollada ao concepto de "turistificación" desde o dereito e un percorrido polos instrumentos administrativos que o abordan cunha correcta combinación dos recursos que outras disciplinas (socioloxía, xeografía, etc.) poden ofrecerlle ao dereito para a análise dun fenómeno complexo.

En terceiro lugar, María del Mar Caraza presenta unha análise da regulación andaluza de vivenda protexida. O seu traballo explora os principais instrumentos habitacionais do corpus lexislativo andaluz e comenta en detalle os criterios de adxudicación e distribución, os sistemas de axudas e outros mecanismos de intervención.

A súa análise identifica os puntos fortes e os puntos febles do modelo de vivenda social andaluz. Conclúe a necesidade de seguir despregando medidas e destinando recursos para reforzar o sistema e, así mesmo, apunta a necesidade de colaboración entre a Junta de Andalucía e as demais Administracións competentes. En particular, o traballo de Caraza é interesante na medida en que enriquece o estudo dos sistemas de vivenda que comezaron a configurarse desde o xiro pro-vivenda da lexislación autonómica desde 2013. 
Posteriormente, no cuarto dos artigos Mauricio Ruíz detense a explorar o dereito a un entorno de calidade. Trátase dun lugar común na literatura especializada que, porén, non foi aínda consensuado. No seu traballo Ruíz reflexiona sobre a lagoa normativa que existe respecto deste concepto no noso ordenamento. Conclúe a necesidade de configurar esta lagoa para dotar de plena efectividade o dereito de vivenda.

A súa contribución ofrece unha análise comparada de distintos textos internacionais, presentes e históricos. A súa análise afonda na lexislación vixente e aproxímase ao concepto desde unha perspectiva fundamentalmente xurídco-dogmática. Por iso, o traballo de Ruíz non é, unicamente, unha chamada de atención sobre esta cuestión. É tamén unha interesante proposta de reconstrución do núcleo constitucional de adecuación e dignidade do dereito á vivenda e dos estudos sobre a segregación habitacional.

Na quinta das colaboracións, Montserrat María Otero aborda a cuestión dos procesos de turistificación e xentrificación desde a perspectiva da planificación urbanística. Esta técnica, característica dos sistemas urbanísticos europeos continentais, é identificada pola literatura coma un recurso potencialmente eficaz fronte a determinadas externalidades negativas do fenómeno da turistificación.

No seu artigo, Montserrat Otero analiza en profundidade o encaixe no noso ordenamento e a conveniencia no noso contexto social e económico actual. Neste sentido, a colaboración de Otero é moi interesante pois detense a estudar a compatibilidade coa Directiva de Servizos das medidas de zonificación.

Para a autora, a planificación urbanística é un instrumento útil fronte ás principais externalidades dos procesos de concentración turística. Non obstante, sinala tamén a necesidade de ponderar os intereses en xogo e moderar a intensidade da intervención. Unha intervención excesiva ou inadecuada pon en risco a mesma sustentabilidade que se persegue a través da planificación.

Finalmente, pecha este número a colaboración de Roberto Bustillo. $\mathrm{O}$ autor reflexiona sobre un extremo vinculado ao concepto de dereito á cidade e ao dereito ao ambiente adecuado que é o de "paisaxe". Na medida en que a paisaxe é un ben xurídico perceptible por máis dun único sentido, Bustillo explora os beneficios da protección xurídica da paisaxe e os seus efectos nas persoas con discapacidade. O traballo de Bustillo é unha chamada a reflexionar sobre a complexa configuración xurídica deste concepto. Mais tamén sobre a necesidade da articulación destas medidas polo profundo impacto que este ben xurídico ten no desenvolvemento da personalidade. 